\title{
Influence of Teacher-Student Matching on Knowledge Innovation of Graduate Students
}

\author{
https://doi.org/10.3991/ijet.v15i20.17421 \\ Jingui Wang \\ Hebei University of Engineering, Handan, China \\ Yanming Qi $\left({ }^{\square}\right)$ \\ Hebei University of Engineering, Handan, China \\ 55417999 dqq. com
}

\begin{abstract}
The teacher-student (T-S) matching in colleges has not been studied in a thorough and systematic manner. It remains unclear how college T$\mathrm{S}$ matching affects the knowledge innovation of graduate students. Therefore, this paper firstly analyzes the factors affecting the knowledge innovation of graduate students and selects the T-S matching mode that promotes their knowledge innovation. Then, the promotion of knowledge innovation was investigated under the T-S matching. Finally, the authors quantified the importance of knowledge innovation among graduate students and summarized the strategies and methods for cultivating innovation ability based on T-S matching. The research results provide a panoramic view of the cultivation of innovation ability among graduate students from the angle of T-S matching.
\end{abstract}

Keywords-Higher education, knowledge innovation, teacher-student (T-S) matching, graduate students, innovation ability.

\section{$1 \quad$ Introduction}

Higher education plays a very important role in promoting the training of senior talents. Following the continuous development of higher education, the ability training of college students is also constantly improving [1-2]; especially with the wide application of emerging intelligent technology in higher education, higher requirements have been proposed for the improvement of comprehensive quality such as innovation ability in the training process of college student [3-5]. Colleges focus on the cultivation of innovation ability among graduate students and undergraduates, which two have different goals and requirements. Undergraduate training emphasizes the cultivation of students' basic professional qualities, while graduate training focuses on cultivating graduate students' strong sense and ability of scientific research innovation, to independently solve scientific research problems [6-8]. For this, more and more researchers have carried out relevant academic research and exploration on the knowledge innovation ability of college students, and given some corresponding strategies and methods, which are very good for improving students' knowledge inno- 
vation. For example: Cheng et al. [9] analyzed the impact of college campus culture on college students' knowledge innovation. Aichouni et al. [10] took Saudi students as the research object, conducted research and analysis on improving their creativity and innovation ability, established a theoretical research framework, and designed a questionnaire. Wang [11] discussed the knowledge innovation of graduate students from the perspective of personal knowledge management. Li and Wang [12] took the university students majoring in electronic information as the research objects and studied the cultivation of students' innovation ability. Fu et al. [13] investigated and analyzed the status quo of postgraduate knowledge innovation in recent years and summarized some conclusive results. Amornkitpinyo and Wannapiroon [14] researched and analyzed a causal relationship model of the acceptance process of innovative technology for graduate students in the 21 st century.

However, the current research on the cultivation of graduate students' knowledge innovation is still not systematic and complete. It's unclear on how the T-S matching affects the cultivation of graduate students' knowledge innovation. To this end, based on the relevant research results, this paper studies the influence of college T-S matching on graduate students' knowledge innovation, and puts forward related strategies and methods. It consists of 6 parts. The first part gives an overview about the current cultivation of college students' knowledge innovation ability; the second part discusses the factors affecting the knowledge innovation of graduate students; the third part analyzes the influence of T-S matching mode on the cultivation of innovation ability; the fourth part proposes the implementation method of cultivating graduate students' knowledge innovation based on T-S matching; the fifth part quantified the importance of knowledge innovation among graduate students; the sixth part gives the conclusion of this study.

\section{Analysis for Factors Affecting Current Knowledge Innovation of Graduate Students}

Graduate students and undergraduates have different training objectives and requirements. For the undergraduates, it is generally required for them to have a solid theoretical foundation and be able to solve design problems in engineering design based on the acquired professional knowledge they have learned. For the graduate students, they should possess strong professional knowledge, the ability to independently undertake scientific research projects and solve scientific research problems, and the ability to deepen and expand professional design, which all requires strong knowledge innovation ability. Thus, it is the core of graduate education in colleges on how to effectively enhance the knowledge innovation ability of graduates' students and ensure the training quality. But currently there are still several factors affecting the cultivation of graduate students' knowledge innovation ability as follows: 


\subsection{The faculty of the post-graduate major}

The cultivation of graduate students is generally implemented in terms of disciplines and majors. It is often subdivided into multiple majors. From the perspective of the ratio of faculty, the faculty varies in different majors, which is generally reflected in the ranking of the major's comprehensive strength among similar colleges, the proportion of senior title, whether it is a key discipline or major, whether there are key laboratories, number of international or domestic senior talents in the major, highlevel international or domestic scientific research projects undertaken, and awards of scientific and technological achievements, etc. Generally, in addition to providing better basic scientific research conditions for postgraduate training, disciplines or majors with strong faculty can also ensure the postgraduates to study the latest frontier scientific issues, expand scientific thinking ability and scientific research practical ability, and obtain new scientific research results under the guidance of a high-level teacher team. Whereas, the discipline or major with poor faculty will be difficult to keep up with the development trend in the new era and to ensure the quality of postgraduate training, resulting in the weak comprehensive quality and the innovation ability of the graduate students. Thus, the cultivation quality of graduate students in disciplines and majors with strong faculty is generally higher than that with ordinary teachers, which is also verified in the existing research results. As above, the promotion of professional faculty for graduate students plays an important role in the cultivation of their knowledge innovation ability.

\subsection{The professional qualities of the supervisors}

College students generally do not have a designated supervisor; they are taught mostly in large groups for professional basic courses and meet the graduation requirement by finally passing the exams of various courses and completing professional course design with a certain workload. Unlike the college students, the graduate students have a fixed supervisor, and carry out professional scientific research under the guidance of the supervisor. Generally, the number of graduate students enrolled by the supervisor each year is limited, and only a few students can make exchanges with the supervisor. The research objects and tasks of graduate students are generally closely related to the research directions and topics of the supervisors. Thus, the supervisor's professional quality directly affects the cultivation of graduate students. If the supervisors are good in professional quality, it cannot only deepen the research topic of graduate students and broaden the research perspective, but also well guarantee the academic knowledge and scientific research conditions required by graduate students to carry out research tasks, and help the solution of scientific research problems, thereby improving the knowledge innovation ability of graduate students. Conversely, if the supervisors are poor in professional quality, they cannot effectively provide the above-mentioned support to the graduate students they supervise, making it difficult to achieve the goal of graduate training, and further restricting the cultivation of their innovation ability. For this reason, the selection of an appropriate supervisor is a key link to enhance the knowledge innovation ability of graduate students. 


\subsection{Laboratory team building of supervisors}

The laboratory team building of the supervisors involves two aspects: one is whether it's well graded, that is, an echelon-type talent team is formed; the other is whether it has a good scientific research atmosphere or environment. If the laboratory team has an echelon-like talent structure, it indicates that the scientific research innovation of the supervisors has good sustainability and developability, which helps graduate students not only to quickly grasp the existing research results of the scientific research team, but also learn the latest scientific research developments. This has a promotive effect on the subsequent cultivation of graduate students' innovation ability. Besides, a good scientific research atmosphere or environment in the laboratory means that the cultivation of graduate students is in an active state, and the trained graduate students tend to subtly enhance their own scientific research quality, thereby improving their own scientific research innovation ability. On the contrary, the poor laboratory team building may cause the graduate students to fail in acquiring cuttingedge scientific research materials and develop a procrastinating research habit, which is not obviously conducive to the cultivation of graduate students' knowledge innovation ability.

\subsection{Personal scientific literacy of graduate students}

The graduate students are encouraged to develop good personal scientific literacy. First, they must correct their attitudes toward scientific research. When graduate students enter the postgraduate study stage or the scientific research team of supervisors, it may be difficult for them to quickly keep up with the pace of scientific research due to weak basic knowledge or professional knowledge. If individuals can correct their learning attitudes and continue to learn new knowledge, they will certainly be able to quickly involve in the scientific research of the supervisors. Secondly, graduate students themselves must develop good research habits. The goal of graduate training is to cultivate independent research innovation ability of graduate students. This requires the graduate students to emphasize on the accumulation and management of scientific knowledge, well implement the scientific research plan of every stage, verify the results of scientific research experiments with a rigorous scientific research attitude, and complete scientific research tasks objectively and seriously. Under the guidance of the supervisors, only through the continuous efforts and improvement of the graduate students, can they obtain scientific research wealth more effectively, thereby improving the knowledge innovation ability in a targeted manner.

\section{Influence of T-S Matching on The Cultivation of Innovation Ability among Graduate Students}

The above analysis shows that the professional strength of the school's faculty, the professional quality of the supervisor, the laboratory team building of the supervisor, or the cultivation of the personal scientific literacy of the graduate student are all 
directly or indirectly related to the supervisors of the graduate student. Therefore, the selection of a suitable T-S matching mode will be more conducive to the cultivation of graduate students' innovation ability. For this, it needs to consider the T-S matching in the following aspects.

\subsection{Scientific research interests}

The T-S matching in the scientific research interests mainly refers to the degree of consistency between the personal interests and hobbies of the graduate students and the scientific research direction or content of the supervisors during their scientific research. Formally, the research directions of supervisors can be roughly divided into three types: academic research, engineering research and compound research. Academic research focuses on theoretical analysis and discussion; engineering research is for the practical scientific research projects; compound research involves both academic research and engineering research. From the perspective of graduate students, some have strong practical skills but weak theoretical analysis capabilities; some are good at theoretical absorption capabilities, but weak in the practical capabilities; others may have both theoretical analysis and scientific research practical capabilities. This may lead to different research interests of graduate students. They may be interested in academic research based on theoretical analysis, engineering research based on scientific research project development, or the compound research. The close T-S matching in the research interests is the first step for graduate students to study the scientific issues. It can stimulate both graduate students and supervisors to carry out scientific research, and acquire and manage research knowledge, thereby effectively promoting scientific research and improving the innovation ability of graduate students.

\subsection{Scientific research values}

The T-S matching in scientific research values mainly refers to the degree of consistency in the awareness and understanding of scientific issues between graduate students and supervisors in the process of scientific research. Generally, due to the accumulation of more research experience and the exposure to more cutting-edge scientific information, the supervisors have more professional and academic knowledge accumulation and reserves in scientific research. Their perspectives of scientific research are diversified, and knowledge and understanding of the scientific research are relatively deep. As a new force for scientific research, graduate students are obviously weak in the accumulation and reserve of scientific research knowledge. But if they can recognize the supervisors in terms of the cognition and understanding of scientific research issues, get closer to their scientific research direction, or remain consistent with the scientific research culture of the supervisor's team, then the graduate students shall be able to quickly expand their scientific research knowledge reserves, avoid detours in solving scientific research problems, and analyze scientific research issues in depth and breadth. This plays an important role in broadening the 
perspective of graduate students, enhancing their ability to absorb scientific research knowledge, and improving their knowledge innovation ability.

\subsection{Scientific research goals}

The T-S matching in scientific research goals mainly refers to the degree of consistency in the scientific research goals that graduate students and supervisors ultimately expect to achieve during the scientific research. In this study, the scientific research goals are more focused on solving scientific research problems to obtain research results or achievements finally. From the perspective of supervisors, the scientific research goals for training graduate students generally include two levels: One is to enable them to complete scientific research tasks well, to have a deeper understanding and discussion of the research issues being studied, and to propose innovative opinions; the other level is the ability to form relatively systematic and high-level research results for scientific research issues, including scientific research reports, papers, patents, etc., and then to successfully complete personal studies. From the perspective of graduate students, the scientific research goals are more focused on how to successfully complete scientific research tasks and meet individual academic requirements. In this process, they may not pay attention to the acquisition of innovative scientific research results. Generally, the scientific research goals of the two above are well combined in the implementation of scientific research tasks. When making reasonable scheme design, schedule planning, model establishment, method application, and results display of scientific research projects, the scientific research knowledge are generated, as an important supplement to the graduate, which has a great effect on improving graduate students' knowledge innovation ability. Therefore, the better matching in the research goals between graduate students and supervisors is more favorable to the progress of graduate students' scientific research work, and absorption of graduate research innovation knowledge.

\subsection{Scientific research quality}

The T-S matching in scientific research quality matching mainly refers to the degree of consistency between graduate students and supervisors in terms of scientific research awareness, spirit, and methods during the scientific research. The matching of scientific research awareness is mainly the desire for discovery, capture, and solution of scientific research problems by graduate students and supervisors; with the stronger desire for exploration, they shall be more eager for acquisition and innovation of scientific research knowledge. It is the driving force for the development of scientific research projects based on knowledge innovation. The matching of scientific research spirit refers to the spiritual power of graduate students and supervisors such as innovation, fearlessness, cooperativeness, and active exploration in the process of scientific research; the stronger the spiritual power, then the more conducive it is to the solution of complex scientific research problems, and to the absorption and accumulation of scientific research knowledge. The matching of scientific research methods emphasize the ability of graduate students and supervisors to apply some 
methods and experiences in the process of scientific research, such as the methods to select topics for scientific research projects, design schemes based on scientific research needs, include them in design schemes for data collection, summarization and organization, conduct experimental research on design issues, process and analyze data on scientific research issues, extract research results on scientific issues, and form research reports on scientific issues, etc. This is a process of recognizing, understanding, and deepening scientific research knowledge. The above three aspects of scientific research quality do not exist independently. As an organic whole, they are interdependent and mutually exist in the process of cultivating graduate students' knowledge innovation behavior. Thus, the higher matching degree of scientific research quality between graduate students and supervisors is more conducive to the accumulation and application of scientific research knowledge, the improvement of their knowledge innovation ability, and the cultivation of scientific research innovation ability.

\subsection{Character and personality matching}

Character and personality matching mainly refers to the compatibility, complementarity and coordination of character and personality between graduate students and supervisors in the scientific research. From the perspective of psychology, the character and personality traits of individuals will affect their specific behavior under the action of external situational factors, that is, there is a character and personality matching relationship between people, and the strength of this matching relationship directly affects the behavior of the individual. Then, in the process of scientific research, there will also be a matching relationship of character and personality matching between graduate students and supervisors. If there is a better matching in the compatibility, complementarity, and coordination of character and personality between them, the graduate students shall take a more positive scientific research attitude towards the scientific research projects of the supervisors, and better cooperate with the supervisors or team members in academic exchanges, scientific research discussions, and knowledge sharing. Thus, they will be able to integrate into the scientific research team of the supervisors more quickly, obtain richer scientific research knowledge, and further produce higher evaluation and absorption of scientific research knowledge, thereby forming a virtuous circle of the acquisition, absorption and application of scientific research knowledge, and providing an effective support for graduate students to carry out scientific research. The good matching in the character and personality acts as a catalyst for the cultivation of graduate students' knowledge innovation ability.

\section{Implementation Methods for the Cultivation of Graduate Knowledge Innovation Based on T-S Matching}

The essence of graduate students' knowledge innovation is that individual graduate students can continuously learn and expand professional knowledge on the basis of 
existing scientific research knowledge, and realize its recognition, understanding and accumulation; then, guided by the accumulated scientific research knowledge, they can solve the design problems in the operation of scientific research projects, and obtain innovative scientific research results with theoretical or engineering applications. Therefore, based on T-S matching, the authors proposed to effectively cultivate graduate students' knowledge innovation from the following aspects: knowledge acquisition, knowledge management, knowledge creation, and knowledge application of graduate students.

\subsection{Knowledge acquisition of graduate students}

Knowledge acquisition means that graduate students analyze, study, summarize and organize various design knowledge sources through different acquisition methods, and extract various forms of knowledge for scientific research. It is the primary link for graduate students to carry out knowledge innovation, and the basic prerequisite for the establishment of their personal scientific research knowledge system. In the process of acquiring knowledge, the focus must be on solving three problems: the first is what research knowledge to acquire; for the scientific issues, some research tasks are often interdisciplinary or interprofessional, which requires graduate students to determine the subject matter of scientific research knowledge to be acquired and then to screen the knowledge sources in a targeted manner. The second is the type of knowledge to be acquired; in terms of the forms of knowledge, knowledge is often displayed in various forms such as text, graphics, tables, models, formulas, functions, and data sheets, and the related medium includes paper books, databases, knowledge bases, and electronic documents, etc. Therefore, it is very necessary to select the appropriate knowledge expression form according to the needs of the individual research tasks of graduate students. The third is the means and methods used for knowledge acquisition. For graduate training, the curriculum setting is mostly based on the teaching of professional knowledge within the discipline, supplemented by professional knowledge across disciplines. The knowledge acquisition of graduate students is still closely related to the scientific research carried out by graduate students. For this, the methods and means of knowledge acquisition are still reflected in professional course learning, literature review, teacher-student exchanges, team member exchanges of supervisors, academic conferences, scientific research practice projects, etc. Besides, with the rapid development of modern science and technology, various emerging intelligent technologies such as virtual reality technology, network technology, information technology, and big data technology, etc. have begun to be applied in higher education [15-18], providing many new methods and means for knowledge acquisition of graduate students. The reasonable application of these methods and means will greatly improve the efficiency and quality of graduate students' knowledge acquisition, thereby enhancing their knowledge innovation ability. 


\subsection{Knowledge management of graduate students}

Knowledge management of graduate students is not a simple knowledge preservation, but to absorb and digest the acquired scientific research knowledge in a reasonable or appropriate way or format, and then provide support for subsequent scientific research projects. It is the driving link for them to carry out knowledge innovation, and the guarantee for scientific research based on the personal scientific research knowledge system of graduate students. This process mainly involves two aspects: The first is the way of knowledge management. For the research on scientific issues, the scientific research knowledge involved is generally domain-based. The management and analysis of various types of scientific research knowledge in the field generally requires to establish the subject words or keywords of various scientific research knowledge within the domain, which is conducive to the classification, the retrieval, and matching of knowledge; moreover, due to the diversity of knowledge, different forms of scientific research knowledge often need to establish corresponding knowledge bases, such as the engineering database, graphics database, model database, case database, and method base and so on. The second is the type of knowledge model for knowledge management. Scientific research knowledge is very complicated, so it is necessary to adopt appropriate knowledge models for knowledge modeling in the process of knowledge management. Knowledge modeling often needs to be analyzed in combination with specific knowledge properties. In general, knowledge hierarchical management or knowledge fragmentation management should be also conducted for complex scientific research knowledge, and then corresponding knowledge units are formed for storage. The knowledge models formed by knowledge modeling include chart form, tree form, semantic structure, frame form, production rules, predicate structure, object-oriented structure, and image, voice, and video forms etc. Effective management of knowledge can realize the accumulation, absorption, and digestion of graduate students' scientific research knowledge, and then support for subsequent postgraduate knowledge creation and knowledge application, thereby improving their ability to solve scientific research problems.

\subsection{Knowledge creation of graduate students}

Knowledge creation refers to the process of absorbing knowledge and transforming it into new knowledge through effective management and knowledge sharing based on knowledge acquisition. It is the deepening link of knowledge innovation, and the implementation link of scientific research based on the personal scientific research knowledge system of graduate students, which is of great significance to the transformation of scientific research knowledge. In this paper, the knowledge creation for graduate students was explained in the three aspects: One is to solve the feasibility analysis of scientific research tasks. The ultimate training goal of graduate students is to cultivate their ability to independently solve scientific research problems, which is mainly reflected in whether graduate students can decompose the design process, analyze design problems, formulate design schemes, and establish design models according to the scientific research problems to be solved. In this process, the existing 
reserves of scientific research knowledge need to be used for the feasibility analysis of the above-mentioned links. If the solution is successfully obtained, the scientific research knowledge gained in this process is the sublimation of knowledge management. The second is to solve the problem of knowledge sharing. Only through constant knowledge sharing and learning can the knowledge of graduate students continuously generate new knowledge. For knowledge sharing, it must consider what knowledge to share, the way to share, the objects of knowledge sharing, and the scope of knowledge sharing. The knowledge sharing aims to encourage the creation of graduate students' personal scientific research knowledge, so the knowledge to be shared must be based on the professional knowledge of graduate students. Moreover, due to the continuous advancement of modern science and technology, graduate students must be good at applying advanced technical means such as network technology, Information technology, computer technology, etc. to realize the sharing of knowledge. The objects of knowledge sharing can be divided into two types; the professional or academic experts, scholars and colleagues in the broad category, and supervisors and their talent team in the narrow category. The corresponding forms of knowledge sharing include experience exchange, academic discussion, and technical analysis, etc. The third is the manifestation of knowledge creation, which generally includes postgraduate academic papers, patents, standard or specification formulation, monographs or translations, software copyrights, science and technology competitions, and science and technology projects etc.

\subsection{Knowledge application of graduate students}

The knowledge application refers to a process in which the graduate students transform the acquired, absorbed, and digested knowledge from theoretical aspects to practical activities based on knowledge acquisition, knowledge management and knowledge creation. Obviously, it's an organic integration of knowledge acquisition, knowledge management, and knowledge creation, and the ultimate manifestation of knowledge innovation, playing a crucial part of the cultivation of graduate students' knowledge innovation ability. The knowledge application effect of graduate students directly determines whether the training of knowledge innovation is successful. For this, the knowledge application of graduate students needs to consider the two aspects: the combination of theoretical knowledge and practical activities, and the specific implementation of knowledge application. As we know, knowledge is meaningful and valuable only when it is applied. Only when graduate students can effectively transform various forms of scientific research knowledge acquired into various scientific research activities for solving scientific research tasks, such scientific research knowledge shall have corresponding scientific research value. The combination of theoretical knowledge and practical activities is analyzed to determine whether theoretical knowledge can be effectively absorbed and transformed in the process of scientific research activities, thereby expanding graduate students' scientific research thinking and forming an effective solution to scientific research problems, rather than only focusing on the theoretical knowledge. This doesn't mean that academic research is not important, but that the goal of academic research must form theoretical support 
for scientific research practice. Such academic research is more conducive to the cultivation of graduate students' knowledge innovation ability. The specific implementation methods of knowledge application are diverse among graduate students, e.g., graduate thesis writing based on scientific research issues, participating in scientific research projects of supervisors or teams, participating in science and technology competition projects, undertaking science and technology innovation funds alone or in teams, and participating in Industry-university-research projects, etc. All these methods can be carried out simultaneously. Any implementation method that is conducive to the transformation of graduate students' scientific research knowledge can be integrated into the cultivation of graduate students' knowledge innovation.

\section{Analysis for the Importance of Knowledge Innovation Ability among Graduate Students}

The above analysis found that the cultivation of graduate students' knowledge innovation is mainly affected by the four links of knowledge acquisition, knowledge management, knowledge creation and knowledge application. But each link has a different degree of effect on graduate students' knowledge innovation ability. For this, the importance of knowledge innovation among graduate students was quantified to ensure the influence of each link on the cultivation of graduate students' knowledge innovation ability in a hierarchical and quantifiable manner. On this basis, the strategies and methods for cultivating innovation ability based on T-S matching were proposed, to provide effective support for the cultivation of knowledge innovation. When different higher education managers or college leaders analyze the importance of the above four links, they may have different analysis perspectives, and the importance indicators of each link determined from this may often vary. The author believes that regardless of the important indicators used, the most important is that knowledge acquisition must reflect the ability to extract knowledge, knowledge management must reflect the absorptive capacity of knowledge, knowledge creation must reflect the ability to innovate, and knowledge application must reflect knowledge transformable capacity. After obtaining the importance indicators of knowledge innovation ability, it's necessary to analyze the importance of these indicators.

There are many methods of importance analysis [19-22]. But due to certain factors, specific data information cannot be obtained, or some data information is missing or omitted, so that there is certain limitation for the methods which have requirements for data sample size or the quantification of specific data information. For this reason, this paper uses AHP method to analyze the importance of graduate students' innovation ability. The AHP method is a multi-criteria and multi-factor decision-making method that quantitatively analyzes qualitative problems. It can classify the various factors in the process of complex system problem processing in an orderly manner, and integrate the researcher's objective judgments with expert opinions, thereby achieving the importance analysis of elements through the pairwise comparison, and a wide range of applications in the engineering field [23-26]. The specific implementation steps are as follows. 
Step 1: establish the importance index system of graduate students' knowledge innovation in a hierarchical structure and assume that the index system has $\mathrm{n}$ importance indicators under the same hierarchical structure.

Step 2: build a judgment matrix A corresponding to the importance index system through pairwise comparison of the importance indicators.

$$
\mathbf{A}=\left[\begin{array}{ccccc}
a_{11} & \cdots & a_{1 j} & \cdots & a_{l n} \\
\vdots & \vdots & \vdots & \vdots & \vdots \\
a_{i 1} & \cdots & a_{i j} & \cdots & a_{i n} \\
\vdots & \vdots & \vdots & \vdots & \vdots \\
a_{n 1} & \cdots & a_{n j} & \cdots & a_{n n}
\end{array}\right]_{n \times n}
$$

where, aij indicates the importance degree of the importance indicator i relative to $\mathrm{j}$, aij=1/aji, and the number can be marked using the 1-9 ratio scale method.

Step 3: use the square root method to solve the judgment matrix A, obtain the matrix normalized eigenvector and matrix eigenvalue, and derive the weight wi of the indicator $\mathrm{i}$ and the corresponding weight sequence $\mathrm{W}$ :

$$
\begin{gathered}
w_{i}=\sqrt[n]{\prod_{j=1}^{n} a_{i j}} / \sum_{i=1}^{n} \sqrt[n]{\prod_{j=1}^{n} a_{i j}} \\
\mathbf{W}=\left\{w_{1}, \cdots, w_{i}, \cdots, w_{n}\right\}
\end{gathered}
$$

Step 4: derive the largest characteristic root $\lambda \max$ of the judgment matrix A:

$$
\lambda_{\max }=\sum_{i=1}^{n} \frac{\left(\mathbf{A} W^{T}\right)_{i}}{n w_{i}}
$$

Step 5: perform consistency test analysis on the judgment matrix A, namely

$$
\begin{gathered}
C I=\left(\lambda_{\max }-n\right) /(n-1) \\
C R=C I / R I
\end{gathered}
$$

$\mathrm{RI}$ is the average random consistency index, which can be obtained by querying the average random consistency index numerical table.

If satisfying the following conditions, namely

$$
C R<0.1
$$

It indicates that the judgment matrix A satisfies the consistency requirement, that is, the weight distribution of each importance indicator in the importance index system is reasonable, and the importance analysis ends. Otherwise, proceed to the next step. 
Step 6: if A does not meet the consistency requirements, re-evaluate the importance of the importance indicator i relative to $\mathrm{j}$, adjust to obtain a new judgment matrix $\mathrm{A}$, and repeat steps 1 to 5 until the consistency requirements are met.

\section{Conclusion}

This paper studies the influence of college T-S matching on the knowledge innovation of graduate students. For this, a comprehensive analysis was conducted about the factors affecting the knowledge innovation ability of graduate students mainly on the theoretical level, the selection of T-S matching mode for the cultivation of innovation ability, and the related implementation methods based on T-S matching from the multi-level and multi-perspective. As a new supplement to the existing research results in theoretical analysis, this study has good theoretical innovation. In addition, considering the hierarchical characteristics of the factors affecting the knowledge innovation of graduate students, this paper performs the importance analysis for the knowledge innovation of graduate students based on the AHP, which can effectively support the analysis for the influence of college T-S matching on graduate students' knowledge innovation ability.

\section{$7 \quad$ References}

[1] Osman, A.S.A., Faizal Khan, Z. (2019). Novel methodology for arbitration of talented students using an electronic system: A higher education perspective, International Journal of Emerging Technologies in Learning, 14(21), 250-257. https://doi.org/10.3991/ijet.v14i $\underline{21.10916}$

[2] Ciesielkiewicz, M., Wisser, W., Rozells, D. (2019). International perspectives on ePortfolios in higher education: Case studies from Asia, North America and Europe, International Journal of Emerging Technologies in Learning, 14(21), 96-109. https://doi. org/10.3991/ijet.v14i21.11048

[3] Deb, K., Banerjee, S., Chatterjee, R. P., Das, A., Bag, R. (2019). Educational website ranking using fuzzy logic and k-means clustering based hybrid method. Ingénierie des Systèmes d'Information, 24(5), 497-506. https://doi.org/10.18280/isi.240506

[4] Jackson, N.C. (2019). Managing for competency with innovation change in higher education: Examining the pitfalls and pivots of digital transformation. Business Horizons, 62(6): 761-772. https://doi.org/10.1016/j.bushor.2019.08.002.

[5] Jahnke, I., Liebscher, J. (2020). Three types of integrated course designs for using mobile technologies to support creativity in higher education. Computers \& Education, 146: 103782. https://doi.org/10.1016/j.compedu.2019.103782.

[6] Hasanudin, C., Fitrianingsih, A., Sadhono, K. (2019). How is the student's negotiation text in collaborative learning of flipped classroom and a CyberLink power director media apps. Ingénierie des Systèmes d'Information, 24(6), 559-567. https://doi.org/10.18280/isi.24060 1

[7] Liu, H.Y., Chang, C.C., Wang, I.T., Chao, S.Y. (2020). The association between creativity, creative components of personality, and innovation among Taiwanese nursing students. Thinking Skills and Creativity, 35: 100629. https://doi.org/10.1016/j.tsc.2020.100629. 
[8] Chen, A., Li, L., Li, X., Zhang, J., Dong, L. (2013). Study on innovation capability of college students based on extenics and theory of creativity. Procedia Computer Science, 17: 1194-1201. https://doi.org/10.1016/j.procs.2013.05.152.

[9] Cheng, G., Wu, D.M., Xu, X.T. (2018). The Influence of Campus Culture on University Students' Knowledge Innovation. Information Research, (7): 1-16. https://doi.org/10.3969/ j.issn.1005-8095.2018.07.001.

[10] Aichouni, M., Touahmia, M., Al-Ghamdi, A., Ait-Messaoudene, N., Al-Hamali, R.M., AlGhonamy, A., Al-Badawi, E. (2015). Creativity and innovation among gifted saudi students-an empirical study. Procedia-Social and Behavioral Sciences, 195: 1371-1379. https://doi.org/ 10.1016/j.sbspro.2015.06.403.

[11] Wang, Q. (2014). Postgraduates' knowledge innovation under the perspective of personal knowledge management. Higher Education Forum, 2014(2): 104-107. https://doi.org/10.39 69/j.issn.1671-9719.2014.02.030.

[12] Li, H., Wang, W. (2012). Research on Improving Innovative Ability of College Students in Electronic Information Major. Procedia Environmental Sciences, 12: 1243-1247. https:// doi.org/ 10.1016/j.proenv.2012.01.415.

[13] Fu, L.H., Bao, D.X., Li, Y.F., Yan, M.Y. Chen, M.H. (2015). Investigation and Analysis of the Current Situation of Graduates' Knowledge Innovation. Innovation Science and Technology, 182(4): 32-36. https://doi.org/ 10.19345/j.cnki.1671-0037.2015.04.009.

[14] Amornkitpinyo, T., Wannapiroon, P. (2015). Causal relationship model of the technology acceptance process of learning innovation in the 21 st century for graduate students. Procedia-Social and Behavioral Sciences, 174: 2090-2095. https://doi.org/ 10.1016/j.sbs pro.2015.02.006.

[15] Fekri-Ershad, S. (2019). Gender classification in human face images for smart phone applications based on local texture information and evaluated Kullback-Leibler divergence. Traitement du Signal, 36(6), 507-514. https://doi.org/10.18280/ts.360605

[16] Subhash, S., Cudney, E.A. (2018). Gamified learning in higher education: A systematic review of the literature. Computers in Human Behavior, 87: 192-206. https://doi.org/10.10 16/j.chb.2018.05.028.

[17] Kim, Y.H., Ahn, J.H. (2016). A study on the application of big data to the Korean college education system. Procedia Computer Science, 91: 855-861. https://doi.org/10.1016/j.proc s.2016.07.096.

[18] Hamidi, H., Chavoshi, A. (2018). Analysis of the essential factors for the adoption of mobile learning in higher education: A case study of students at the University of Technology. Telematics and Informatics, 35(4): 1053-1070. https://doi.org/10.1016/j.tele.2 $\underline{017.09 .016 .}$.

[19] Attarakih, M., Bart, H.J., Abu-Khader, M. (2019). On the solution of the population balance equation: From global to local constrained maximum entropy method. Chemical Engineering Science, 209: 115168. https://doi.org/10.1016/j.ces.2019.115168.

[20] Wolnowska, A.E., Konicki, W. (2019). Multi-criterial analysis of oversize cargo transport through the city, using the AHP method. Transportation Research Procedia, 39: 614-623. https://doi.org/10.1016/j.trpro.2019.06.063.

[21] Gaudêncio, J.H.D., Corrêa, J.É., de Carvalho Paes, V., da Silva Campos, P.H., Turrioni, J.B., de Paiva, A.P. (2019). Hybrid multiobjective optimization algorithm based on multivariate mean square error and fuzzy decision maker. Applied Soft Computing, 82: 105586. https://doi.org/10.1016/j.asoc.2019.105586.

[22] Abdel-Basset, M., Mohamed, R. (2020). A novel plithogenic TOPSIS-CRITIC model for sustainable supply chain risk management. Journal of Cleaner Production, 247: 119586. https://doi.org/10.1016/j.jclepro.2019.119586. 
[23] Giner-Santonja, G., Calvo, V.V., Lepe, G.R. (2019). Application of AHP and corrective factors for the determination of best available techniques and emission limit values at installation level: A case study in four cement installations. Science of the total environment, 660: 834-840. https://doi.org/10.1016/j.scitotenv.2018.12.473.

[24] Vardi, M., Neyestani, M., Ghorbanian, A. (2019). Supplier selection and order allocation problem modeling with the aim of comparing incremental discounts versus wholesale discounts by using GA and NSGA algorithms. Journal Européen des Systèmes Automatisés, 52(1), 23-34. https://doi.org/10.18280/jesa.520104

[25] Butdee, S., Phuangsalee, P. (2019). Uncertain risk assessment modelling for bus body manufacturing supply chain using AHP and fuzzy AHP. Procedia Manufacturing, 30: 663670. https://doi.org/10.1016/j.promfg.2019.02.094.

[26] Wang, W.X. (2019). Site selection of fire stations in cities based on geographic information system (GIS) and fuzzy analytic hierarchy process (FAHP). Ingénierie des Systèmes d'Information, 24(6), 619-626. https://doi.org/10.18280/isi.240609

\section{Authors}

Jingui Wang was born in Yi Country, Baoding city, Hebei Province in September 1980. She graduated from Hebei Agricultural University with a bachelor's degree in 2003 and a master's degree in 2006. Since 2006, She had been working in School of Water Conservancy and Hydroelectric Power, Hebei University of Engineering, engaged in water conservancy and ideological and political education and scientific research for college students. In 2019, She was appointed as an associate professor. Jin-gui Wang had published 8 academic papers on ideological and political education, including 3 core journals, 5 provincial journals, written 1 monograph and edited 1 textbook. Besides, she had presided over 7 provincial scientific research projects, 1 municipal scientific research project and 2 universitylevel scientific research projects over the past five years. She is good at ideological and political education, mental health education, innovation and entrepreneurship education of college students (Email: 55417999@qq.com).

Yanming Qi was born in Handan city, Hebei Province in November 1980. She graduated from Hebei Normal University with a bachelor's degree in 2003 and Hebei University with a master's degree in 2010. Since 2003, I had been working in School of Humanity and Law, Hebei University of Engineering, engaged in Chinese language and literature, ideological and political education and scientific research for college students. In 2015, I was appointed as an associate professor.

Yan-ming Qi had published more than 30 papers, presided over more than 10 provincial and ministerial scientific research projects, published 3 books, and won 5 provincial and ministerial awards. Articles published in the theoretical edition of Guangming Daily were reprinted in large quantities. I am good at ideological and political research and public opinion control of college students (Email: 513995261@qq.com).

Article submitted 2020-07-31. Resubmitted 2020-09-03. Final acceptance 2020-09-05. Final version published as submitted by the authors. 